\title{
Caste, Class, and Urbanization: The Shaping of Religious Community in Contemporary India
}

\author{
Samuel Stroope
}

Accepted: 9 January 2011/Published online: 21 January 2011

(C) Springer Science+Business Media B.V. 2011

\begin{abstract}
Building on the implications of qualitative work from India and urbanism theories, I aim to understand whether religious bonding social capital in contemporary India increases with greater urbanization and whether such increases are moderated by caste or social class position. Results from multinomial logistic regression on 1,417 Hindu respondents in a nationally representative sample of India (World Values Survey-India 2001) indicate that religious bonding is fostered by urbanism and that this association is stronger for upper castes. But there is little evidence that social class similarly moderates the association between urbanism and religious bonding. In light of these findings, religious bonding might be better understood as rooted in the interaction of caste dynamics and changes in the urban environment, rather than as a result of greater affluence. The data are also consistent with work underscoring the importance of disentangling social class and caste among Hindus in contemporary India.
\end{abstract}

Keywords India $\cdot$ Caste $\cdot$ Stratification $\cdot$ Religion $\cdot$ Urbanization $\cdot$ Community

\section{Introduction}

Social scientists since Durkheim, Marx, Weber, and Tönnies have been concerned with the urban environment's role in shaping human community relations. Although early work in this area maintained that urban life largely erodes the strength of community interaction (Wirth 1938), recent scholars, rather than seeing a deterministic progression from rural gemeinschaft to urban gesellschaft, maintain that gemeinschaft is a kind of experience or "mode of relating" that can exist in a wide array of settings, both rural and urban (Calhoun 1998: 381). In a similar vein, Fischer $(1975,1995)$ argues that urbanism, in creating critical mass and group boundaries, may help foster subcultural community. Smith et al. (1998: 90) extend this idea, illustrating that urban environments can intensify people's desire for social interaction within "morally orienting" religious groups. These developments in the

S. Stroope $(\bowtie)$

Department of Sociology, Baylor University, One Bear Place \#97326, Waco, TX 76798-7326, USA

e-mail: Sam_Stroope@Baylor.edu 
study of urban cultural community parallel work on social capital, a growing literature giving attention to community relations (Field 2008), in which religion (Putnam 2000: 65-79) and "moral culture" (Etzioni 2001: 223) play a substantial role. While the examination of social capital has seen a broad increase in recent years involving topics as diverse as civil society and health (Moody and Paxton 2009), there remain pertinent areas with less application. Among these is the study of urban religious social capital, to which considerably less research has been devoted outside of the US or Europe. Fischer (1995: 550-551) drew attention to this when he assessed the use of his theory of subcultural urbanism and highlighted the need for the theory to be explored in "non-American" contexts. Yet these gaps do not in and of themselves warrant research in non-Western urbanism and religious social capital, rather it is subcultural urbanism's relevance to substantive theoretical debates that is its primary value. It contributes to broader discussions in the study of modernity and religion, including claims that as societies modernize and urbanize, religious involvement inevitably diminishes (Norris and Inglehart 2004), and arguments that different societies and even distinct groups within societies may have divergent responses to modernization and urbanization (Smith et al. 1998). India provides an important case with which to explore these issues.

Contemporary India is a key context for considering social change and religious community interaction. Not only is India anticipated soon to be the earth's most populous country, it is also the world's largest experiment in democracy. As a bustling center of religious vibrancy, the birthplace of four major world religions and home to numerous others such as Islam, Christianity, Judaism, and Zoroastrianism, India should be of particular concern to the study of religious social capital. Large scale social change is visible in India, with the reverberations of India's economic liberalization in the 1980s and 1990s evident across the country. Three notable changes of concern in this paper are: (1) swelling urban affluent classes, noted to have tripled in size (Sridharan 2004); (2) changing dynamics of caste (Béteille 1997); and (3) a growing number of Indians living in cities of increasing scale.

Qualitative research on religious behavior in India provides theoretical insight and detailed accounts of local settings, but the broader strokes of religious behavior in India's modernized contexts are left empirically understudied. Scholars continue to produce a growing literature on immigrant Indian religious social life outside of India (George 2005; Kurien 2007; Vertovec 2000; Williams 1992), but in comparison, social scientific studies of modern religious life in India remain few. This is a conspicuous gap considering the local and international religious prominence of India, its rising global economic importance and the large population of the country. ${ }^{1}$ This is not to say that a variety of related disciplines have not produced important work on the subject of religion in India. Anthropologists and sociologists of India have pioneered qualitative studies of village, caste, and kinship (Dumont 1980), some devoting considerable space to religion (Srinivas 1965). Historians, Indologists, and textual scholars trace the development of Indian religious traditions (Michaels 2004); Borooah (2003) and other demographers have examined the varying patterns of fertility among Indian religious groups. Globalized media and religious culture, feature prominently in analyses of modern India (Appadurai and Breckenridge 1995; Derne 2008). Political scientists and others are building a voluminous literature on Hindu nationalism (Van der Veer 1994), yet other aspects of modern Indian

\footnotetext{
1 Indian "secularization" is more akin to the pluralistic US market of religious groups than European secularization (Warrier 2003; Warrier 2005: 159). Transnational activity has become increasingly common for Indian religious groups (Levitt 2004).
} 
religious life are left relatively unattended. Some recent anthropological work examines new forms of urban Indian religious devotion (Warrier 2005), but there do not seem to be any national studies examining factors that influence religious social capital. This paper attempts to contribute toward this need.

Religious social capital is a vast topic and rather than tackle its multidimensionality, my limited goal is to puzzle out two issues. First, residence in larger towns and cities may have a positive effect on religious involvement by affording better access to a wider array of religious organizations (Finke and Stark 2005: 200-204). Alternatively, they may reduce a need for religious involvement because of the material security of modern urban living (Norris and Inglehart 2004). I address this issue by asking: Does urban residence bolster time Hindus spend with others at their place of worship? Second, urbanization may have divergent effects on religious social participation for groups experiencing new economic opportunities (Srinivas 1966: 119) or changes in group relations (Swallow 1982). Which groupings highlighted in qualitative research from India-caste or social class-better explain patterns of religious bonding in Indian cities? In order to address these questions, I first situate ethnographic and theoretical insights on religion in India within broader sociological theories of group behavior, and generate empirical propositions. Then, by selecting salient social statuses and locations, and using one of the few national surveys of India with individual-level religiosity measures, I test empirical hypotheses concerning the social antecedents of religious social capital in the Indian city.

\section{Background}

\subsection{Urban India and Religious Social Capital}

The conceptualization of community as social capital has yielded numerous sociological insights (see Field 2008). Scholars know that social capital can have positive results in areas ranging from the job search, social support, to mental health (Granovetter 1973; Hurlbert et al. 2000; Nooney and Woodrum 2002), as well as negative consequences for those to whom social capital does not accrue (Beyerlein and Hipp 2005; Paxton 2002), confirming that "sociability cuts both ways" (Portes 1998: 18). In order to better understand how social capital correlates with varying outcomes, scholars differentiate between two types of social capital: (1) bridging capital, in which social interaction crosses group boundaries; and (2) bonding capital, in which interactions are frequent and between people with the same characteristics. Although bonding capital can foster belonging and wellbeing within the group, it can also diminish bridging social capital across groups (Putnam 2002) "because group solidarity in human communities is often purchased at the price of hostility toward out-group members" (Fukuyama 2001: 8). The varied effects of bonding social capital, though important, are not of immediate concern here; instead this paper is focused on the social factors that foster religious bonding capital in India, such as urbanism.

Indian cities are multi-ethnic places of tension. For example, Kolkata's (Calcutta) cultural "communities have retained their distinct socio-cultural identities through festivals, educational institutions, clubs, recreational centres, libraries, and newspapers in order to re-establish the communities' distinct socio-cultural identities," and this critical mass not only promotes in-group interaction, but also arouses "intense conflict" (Chaudhuri 2009: 199). But why do these interactive subcultural communities develop in the Indian city? Giddens (1991: 185) contends that the conditions of modernity foster a sense of crisis 
for people, which only relationships with other people can assuage. Ethnographic work on modern Indian religious behavior is in line with this contention, providing evidence that in urban India, the main benefits sought in socially intense religious involvement are a sense of security and meaning in life (Babb 1987: 190-193). Resonant with these insights, Fischer (1975) notes that urbanism promotes social bonding for a variety of subcultures (including ethnic and religious groups). More populated environments intensify the solidarity and social involvement of subcultures because of two main factors: (1) more populous places often have larger numbers of people from distinct cultural groups and so can maintain their institutions and encapsulate members in social networks composed of the subculture; and (2) urban environments are culturally heterogeneous and so inhabitants are more likely to frequently meet other groups with which they are in competition, tension, or conflict. (This friction with out-groups in the densely populated city can bolster group boundaries and in-group solidarity, thus increasing the reserves of bonding capital.) At its heart, this theory of subcultural intensity is about intra-group accessibility, communication (Fischer 1995: 549) and "moral density" (Durkheim [1933] 1997), which are fostered by critical mass (often in cities) and further reinforced by intergroup friction (often found in diverse urban places). Smith et al. (1998) extend Fischer's insights to once dominant religious identities in the United States (i.e., evangelical Protestantism). Their work is particularly relevant here because it illustrates how the subculture in question need not be historically subjugated. The group could be one that was once ascendant, but now has diminishing status, power, and perceives threat to its conception of moral order. The above patterns closely parallel Portes and Sensenbrenner's (1993) notion of "bounded solidarity," as well as research on Hindus in contemporary urban India (Swallow 1982).

In studies of India, social capital largely appears in analyses of socio-economic development (e.g. Bhattcharyya 2004), especially in the Indian village context (Krishna 2007). While not necessarily using the terminology of social capital, researchers have also revealed the importance of religious group interaction among diaspora Hindus (Kurien 2007), and Hindus in India (Hertel 1977). At the outset it is important to acknowledge that Hindu religious behavior is popularly thought of as private and home-based. But it is also important to not overlook the many Hindu group activities beyond the family, such as satsangs, kirtans, and intense collective participation during festival seasons among sectarian and non-sectarian Hindus alike (Shah 2006), but particularly among bhakti devotees (Milner 1994: 197). These religious group activities may take place in private homes but also frequently happen in outdoor and public settings such as temples, mathas (monastic compounds), associational halls, and community centers (Singer 1972). Hindu religiosity is private and individualistic, but it is also broadly collective, perhaps especially so in urban environments.

Secularization theorists who predicted that religious institutions would fade in the face of science, economic growth, and urbanization would be puzzled by the prevalence of temples in contemporary urban India. Step outside a taxi or rickshaw in one of India's growing cities and the top of some temple will peek out between apartment buildings or shopping complexes. This urban temple ubiquity is precisely what urban ethnographers have observed for some time, and they are the ones who have conducted the main analysis of the link between urbanization and temples. Waghorne (2004: 4) in particular documents the contours of a "temple building boom" in Indian cities such as Chennai. This rise in temple building in urban contexts is said to be partly a result of the general expansion of the Indian urban middle class and competitive catering to this population on the part of temples, with a good portion of new temples erected in new suburban developments. In terms of quantitative analysis, economists Ray and Das (2004) find a positive correlation 
between growth in urban population and growth in houses of worship using 1991 and 2001 census data on West Bengal, although this is not the primary focus of their analysis. The availability of places of worship in urban spaces partly explains the use of temples as sites of social bonding.

Studies of new religious movements provide a window into intense religious group social interaction in India's cities (Babb 1987), and highlight the unsettling urban environment's role in promoting bonding with fellow devotees (Kakar 1991; Swallow 1982; Varma 1998). Consistent with the aforementioned urban temple literature, there are also indications that this urban pattern of religious bonding extends beyond new religious movement involvement to more mainstream Hindu religious behavior in cities (Narayanan 1999). Ubiquitous across India, but especially prevalent in cities, Hindu temples are sites of personal interaction and social negotiation (Appadurai and Breckenridge 1976). Templebased social interaction is thus one way to operationalize religious bonding capital for Hindus in India. I derive the following hypothesis from these connections in the above literature.

Hypothesis 1 Urbanism will be positively associated with religious bonding capital.

Beyond urbanism itself, two principal social factors come into relief in explanations of religious bonding among urban Hindus in India: caste and social class. Studies tracking religious behavior in India discuss the urban, affluent, and (at times) the largely upper caste composition of those participating in greater religious bonding (Babb 1987; Kakar 1991; Singer 1972; Swallow 1982; Warrier 2005). But these studies tend to root their key mechanisms in social class without clearly distinguishing it from caste. For example, Warrier (2005) focuses on the middle class aspect of her informants, and mentions their predominantly upper caste composition only in passing. Other scholars take a similar tack, emphasizing a class aspect such as industrialism, but leaving this characteristic largely entangled with the industrialists' caste homogeneity (see e.g., Singer 1972). But others do not take this approach and argue instead that caste and social class have recently become increasingly decoupled (Krishna 2002: 38; Mayer 1997; Sheth 1999: 2504). In fact, one of India's most prominent social anthropologists, Andre Béteille (1997), has argued that in contemporary urban India, income, education, occupation, and wealth are increasingly better markers of social status than caste. There are several reasons for this diminishing correlation between caste and social class in recent decades.

There have been policy and societal shifts in the past fifty or more years that have significantly contributed to the increasing decoupling of caste and socio-economic status. First, occupational and economic lines between castes were partly maintained by the centuries old patron-client relationships of the Jajmani system. ${ }^{2}$ But then, increases in cash-based business dealings came to undermine the rigidity of the patron-client relations (Commander 1983). Part of the result of this development is that lower caste individuals became less constrained from moving into occupations not historically associated with their caste communities (e.g., lower caste barbers becoming business owners). Second, the land ownership monopoly of upper castes was somewhat diminished by land reforms following independence in the 1950s. These reforms significantly redistributed land to lower castes (Dreze et al. 1999). Third, recent decades have seen a shrinking of the gap between the educational attainment of upper castes and lower castes (Krishna 2002).

\footnotetext{
${ }^{2}$ Historically, upper caste land owners (jajman) did not cultivate their own land, but were connected to laborers though the Jajmani system whereby lower castes labored and produced goods and upper castes in turn gave provisions and land.
} 
Affirmative action policies (e.g., college admissions quotas for lower castes) have contributed to this increase. The rise in educational attainment among lower castes is also partly related increasing demand for more highly educated workers in well-paying professions-permitting more educated individuals from various caste backgrounds to secure such jobs. Fourth, affirmative action policies have also reserved a large number of government jobs for lower caste individuals, providing comparatively secure, stable, and often well-paying employment (Béteille 1992). These processes of decoupling of caste and socio-economic status have not always been pleasing to upper castes and have contributed to a sense of unsettling and frustration which I will discuss later as a key pressure toward religious bonding among upper caste Hindus.

The above observations concerning caste-class decoupling correspond with work in an adjacent body of scholarship describing movement from a hierarchical ranking of caste dominance $^{3}$ to an array of horizontally distinct castes that are in competition with one another for civic and material resources amid increasing meritocracy in a capitalist democratic society (Fuller 1997: 22; Mayer 1997; Rudolph and Rudolph 1967). ${ }^{4}$ Taken together, this literature suggests that caste should be disentangled from social class when examining factors contributing to religious bonding, particularly in urban India.

\subsection{Caste and Urban Religious Social Capital}

Urbanization should be more highly associated with religious bonding for upper caste Hindus. Popular discussion surrounding India frequently conflates caste and social class, masking differences between Indian social divisions. Although the subject of caste is fraught with a long history of debate, it remains virtually impossible to examine social life in India without some understanding of caste as a distinct category. Notions of caste hierarchy are typically understood along the lines of Hindu textual sources, ranking people into broad caste categories, or varnas. The first three categories, Brahmins (priests), Kshatriyas (warriers), Vaishyas (merchants), are considered upper castes. Sudras (laborers) or "other backward castes" (OBC) is a large grouping situated next in the caste structure. At the base of the caste hierarchy is a categorization of people traditionally deemed untouchable because of their religiously polluting occupations and activities such as handling leather, cleaning toilets, or disposing of animal carcasses discarded by higher castes (Mendelsohn and Vicziany 1998). They are commonly known as Dalits (the oppressed). ${ }^{5}$

Urban ethnic solidarity has been a central application for the subcultural theory of urbanism. How could this theory shed light on the importance of caste for religious bonding in urban India? Weber (1968) understood caste identity as a hierarchical form of ethnicity status. In contemporary India, though caste advantage persists (Vanneman et al. 2006; Desai and Kulkarni 2008), relations of caste domination may be morphing into a market of horizontally competing castes (Fuller 1997), but these changes can also draw

\footnotetext{
${ }^{3}$ Debates concerning the historical formation of caste are beyond the scope of this paper. See Bayly (1999) for a detailed history of caste in India (see also Cohn 1987; Dirks 1987; Dumont 1980; Milner 1994).

${ }^{4}$ I am in no way suggesting that vertical caste domination or economic advantage no longer exists in India; rather this study follows the lead of others that have observed a diminishing linkage between income and caste, indicating that more insight can be gained by disentangling their separate effects (see Mayer 1997).

5 The English word "caste" is used for two different caste levels in the Indian hierarchy. Varna "castes" are the broad ideal groupings, and jati "castes" are the smaller castes within varnas. Jati castes number in the thousands and may be present across regions of the country, or may only exist in certain regions (Singh 2002).
} 
resistance and retrenchment on the part of those from privileged statuses. Béteille (1991) argues that the changing social norms in India's cities confront upper castes with increased meritocracy. Along these lines, Swallow (1982: 153) observes that upper caste Hindus' traditional authority, social status, and lifestyle have come under threat in India's urban environments:

Most [Indian] urban dwellers nominally accept the official ideology of secularism and egalitarianism, but are often unhappy with its practical consequences. Some... admit when pressed that they really admire, respect and believe in the hierarchical principles underlying the caste order [but]... They continually have to make accommodations in every aspect of their social and religious life. In the new towns and newer suburban sectors... it is often extremely difficult to maintain the cycle of religious observances, or to maintain a network of dependent ritual service caste families.... Careers are, in principle, open to new talents, and old service castes have to compete with newcomers. Traditional patterns of authority are threatened. [High castes] are still very much concerned with the maintenance of their high caste rank and their purity, but... They cannot control their environment to the extent that they once did, yet they can neither easily resort to traditional methods of purification nor in most cases even admit that they have these concerns.

In short, amid such social changes, Swallow asserts urban upper castes are drawn to renewed devotional participation as source of moral order in contemporary urban social life. The above examples resonate with other applications of subcultural urbanism, where characteristics of modernity, such as urbanization, increase the appeal of institutions for groups under perceived embattlement. For such groups, contexts of social change (such as cities) intensify felt needs for "stability" and "assurance" found in religious participation and interaction (Smith et al. 1998: 144).

This idea also matches the community forming power of groups that not only bring people together structurally, but according to Etzioni (2001) also bring people together around shared values and moral cultures, for example religious groups (see also Vaisey 2007). Integrating these ideas, Smith et al. (1998: 90) propose that: "drives for meaning and belonging are satisfied primarily by locating human selves within social groups that sustain distinctive, morally orienting collective identities." In times or situations where moral order is upset—what Swidler (1986: 281) and Wuthnow (1987: 152) call "unsettled periods" or "shifts in the moral order"-people may be especially prone to adjust the strategies used to pursue ends and shape social activity. In other words, these unsettled times allow ideologies to more directly influence changes in "strategies of action" (Swidler 1986: 280). Distinct religious or ethnic groups may react differently to the same "unsettling" time, as for example Catholics and Protestants responded to the Industrial Revolution with dissimilar strategies of action (Handy 1960). Indeed, a similar conclusion was reached by Li et al. (2008) in a study of social mobility and social capital in contemporary Britain - higher social position was found to be associated with increased social capital. I build the hypothesis below by tying together the above strands from ethnographic and theoretical literature on caste (Béteille 1991; Swallow 1982), community (Etzioni 2001; Fischer 1995), and culture (Smith et al. 1998; Swidler 1986; Wuthnow 1987):

Hypothesis 2 Urban upper caste Hindus will be associated with higher religious bonding capital than other Hindu castes. 


\subsection{Class and Urban Religious Social Capital}

The relationship between urbanism and religious bonding should be stronger among more affluent individuals. Fischer (1995: 559) argues that urban environments promote more intense bonding in "class cultures." Class can matter for bonding because shared opportunities and pressures in terms of lifestyle, consumption patterns and educational experiences may bind people along class lines. India's affluent classes ${ }^{6}$ have drawn significant popular commentary in recent years, both sanguine (Das 2002) and critical (Varma 1998). This population segment tripled in size since India's economic liberalization (Sridharan 2004), emerged as a vast global consumer class (Jaffrelot and Van der Veer 2008), and provided a base for Hindu nationalism (Chibber and Mishra 1993). The scale of social change surrounding India's urban affluent classes indicates that they may be experiencing greater social upheaval than other classes, both in terms of new opportunities and greater social disorientation. Aspects of life most likely affected include more disposable income, consumer options, geographic mobility, altered social roles, and increased differentiation of work and domestic life. For Norris and Inglehart (2004), material security should diminish religious involvement, yet others argue these effects may work out differently for various groups (Smith et al. 1998), and there is some reason to believe that affluence may bolster certain domains of religiosity (Demerath 1965; Stark 1996: 36-37). Research in India suggests that as social class changes strengthen, the style of many prosperous urbanites' religious behavior becomes more collective (Babb 1987; Kakar 1991; Singer 1972).

Srinivas (1966) proposes that because Hinduism is less organized than other religious systems, it is more vulnerable to modernity's changes, and that the economically privileged should be more affected by these changes than anyone else. Consistent with Giddens's (1990: 18-21) notions of disembedding and distanciation, and looking to patterns in a variety of religious expressions in India, Srinivas suggests that Hindus participate in voluntary associations in large cities in order to make up for the loss of traditional social and cultural environment. As modernization dissociates Hinduism from the constraints of kinship and village community, it becomes increasingly centered on temples, sects, small worship groups, and pilgrimages. In this way, voluntary associations formed on the basis of caste, language, and religious group become more important in large cities in order to make up for the loss of traditional social and cultural environments (Srinivas 1966: 139-145). Srinivas and others submit that such shifts toward religious bonding may be due in part to both the new cultural freedoms the urban affluent classes feel, "breaking free from the restraints of local habits and practices" (Giddens 1990: 20). For example, Warrier (2005) describes how affluent urbanites' new cultural freedom may be partly due to their distance from the religious culture and practices of parents and extended families. Fastpaced urban professional lifestyles afford little time for elaborate religious rituals (which typically reinforce traditional religious culture), and this distance provides an opening and potential need for other religious involvement to fill the void. This opportunity might lead these urban residents to adopt religious practices that better address fast-paced differentiated lifestyles, such as increased religious bonding (Singer 1972). These explanations are

\footnotetext{
${ }^{6}$ In contrast to the United States, India's old and new affluent classes are referred to both in popular media and scholarly research as the "middle class" or the "upper middle class." In order to reduce confusion in terminology for international readers, I will refer to this growing wealthy minority as India's affluent or economically privileged, rather than middle class. For more on India's affluent classes or middle class see Deshpande (2003) and Fernandes (2006).
} 
in line with others who suggest that affluent urbanites are concerned with finding cultural anchoring amid the social changes surrounding their lives (Babb 1987).

The cultural anchoring theme in social class explanations of urban religious bonding focuses on unsettling and a need for order. In his work on urban religious groups, Babb (1987) argues that the life experiences of India's affluent may create a sense of rootlessness and alienation. Urban affluence comes with greater individual freedom, but also with a sense of disorientation. Under these conditions, urban Hindus de-emphasize private rituals in favor of religious group participation because the rapid change of life creates an emphasis on needing to experience personal security and meaning (Babb 1987: 190-193) found in relational solidarity rather than in devoting effort to privately replicating the details of elaborate rituals at home. Affluent urbanites exposure to and competition with members of out-groups in social and work settings may also promote feelings of unsettling (Béteille 1991). Such urban meritocracy can contradict traditional gender and generational social roles, leaving affluent Hindu urbanites socially disoriented. Greater participation in global mass consumerism also exposes these urbanites to voices that may threaten and critique Hindu religious values, identities, and social roles. For example, in ethnographic research on industrial leaders in contemporary Chennai, Harriss (2003) found that Hindus intensified their religious behaviors partly because of greater awareness of the West's critique of Indian civilization. Possibly as a response to such threats, the Chennai devotees felt a need to band together and show the Indian religious tradition to be a vital modern religious force (Harriss 2003; see also Babb 1987: 200; Swallow 1982: 154). In the face of this configuration of changes, affluent urbanites may sense the opportunity and need to increase the social intensity of their religious involvement in order to bring social and cultural order to their lives.

The above correlations between urbanism theory and research on religious behavior among affluent city-dwelling Hindus suggest the following hypothesis.

Hypothesis 3 Greater affluence among urban Hindus will be associated with greater religious bonding capital.

\section{Data and Methods}

The data for this study come from the 2001 wave of the World Values Survey (WVS), administered by the Department of Political Science, Bangalore University, Bangalore, India. The WVS-India mirrors the core questionnaire of the cross-national WVS program, while incorporating India specific adaptations. The 2001 WVS-India is a nationally representative sample of 2,002 adult Indians aged 18-99 in 18 Indian states, covering nearly $97 \%$ of India's population. The data were collected through face-to-face interviews in 10 languages conducted from August to October of 2001. The WVS-India is an especially valuable data set because few quantitative surveys of India devote space to individual-level questions about religious beliefs and practices. Also, the data are unique because the 2001 wave is the only WVS survey that combines caste membership items with religious behavior items. It is also the only WVS wave to tap a social capital dimension of respondents' outward religiosity - how much time they spend with people at their place of worship. The analyses in the paper are limited to Hindus in the sample because the hypotheses are derived from social science literature pertaining to Hindus in India. 


\subsection{Dependent Variable}

To map Indians' connections to social networks and social activities, the WVS asked respondents how often they spent time in a variety of social contexts. "I'm going to ask how often you do various things. For each activity, would you say you do them every week; once or twice a month; only a few times a year; or not at all? Spend time with: (a) parents or other relatives, (b) friends, (c) socially with colleagues from work or your profession, (d) people at your temple, mosque or gurudwara, (e) or people at sports clubs or voluntary service organization." Item "d", what I call "religious bonding," was reverse coded (0-3) and yielded a response of (0) not at all (18.5\%); (1) a few times a year $(23.7 \%)$; (2) once or twice a month $(28.5 \%)$; (3) weekly $(29.3 \%)$. Though congregational social involvement may be popularly thought of as the sole domain of Christian religious expression, intense religious group activity is also a part of Hindu religious expression, not only among the diaspora (Kurien 2007), but also in India in a variety of home-based settings (Narayanan 1999), as well as in dedicated religious buildings such as temples, religious community halls, and mathas (Harriss 2003; Hertel 1977; Singer 1972). The fielding of this religious social capital question in India allows a unique opportunity for studying a collective dimension of Hindu religiosity, what I refer to in this study as religious bonding capital.

\subsection{Analytic Approach}

In order to examine religious bonding among Hindus in India I used multinomial logistic regression. Multinomial logistic regression does not take into account the ordered nature of outcomes such as the four-point social capital indicator in this study (Menard 2001). However, when regressing an ordered dependent variable, the multinomial approach produces unbiased estimates in comparison with ordinary least squares. In this study, multinomial regression is useful in revealing associations between independent variables and particular levels of religious social capital (i.e., weekly, around monthly, and a few times a year) as compared with no social capital (the comparison point). Ordinary least squares, binary logit, and tobit regression models (available upon request) produce results that do not differ in substantial ways from those presented below. At first glance it would seem that ordered logistic regression would be most appropriate for the distribution of the outcome at hand. Ordered logistic regression accounts for the ordered nature of an outcome with limited points and has no assumption of equal distances between points. It also avoids the potential biases in ordinary least squares estimates. Ordered logistic regression did not give results that differ meaningfully from models below. However, ordered logistic regression was not appropriate for these data because the model violated the proportional odds assumption. For these reasons I present multinomial rather than ordered logistic results.

\subsection{Key Independent Variables}

A subcultural theory of urbanism maintains that, the human density in larger places and cities enables more intense social bonding, including along religious lines (Smith et al. 1998). In order to gauge urbanism, I look at the size of respondents' town or city of residence. This variable is an eight point item that ranges from " 2,000 and less" to "500,000 and more." 
The WVS-India 2001 is the only wave of the WVS that includes information on respondents' caste status. This is noteworthy since even the Indian government's national census does not gather caste information on major caste groups such as the upper caste categories. I measure caste status along traditional major groups with a series of dichotomous variables: upper castes (Brahmin, Kshatriya, and Vaishya $=1$ ), Dalit (Scheduled Castes and Scheduled Tribes $=1$ ), and all remaining caste Hindus are categorized as OBC (Other Backward Castes).

Social class is operationalized here with an India-specific measure of scales of income. This household income item is coded as: (1) Less than 500 rupees per month, (2) 501-1,000 rupees per month, (3) 1,001-3,000 rupees per month, (4) 3,001-5,000 rupees per month, (5) 5,001-10,000 per month, (6) 10,001-20,000 rupees per month, (7) 20,001-30,000 rupees per month, (8) 30,001-50,000 rupees per month, (9) more than 50,000 rupees per month.

\subsection{Control Variables}

In addition to the above key independent variables, I included demographic characteristics that are often associated with religious involvement in sociological models. Gender $(0,1)$, age (18-99), number of children (0-8), and whether the respondent is married $(0,1)$. An India-specific measure of educational attainment is controlled and coded as: (0) nonliterate, (1) literate, but primary school not completed, (2) class 5 completed, (3) class 8 completed, (4) high school completed, (5) some college, (6) college degree, (7) graduate degree, (8) professional or higher research degree.

Politically conservative Hindu nationalism is increasingly salient in recent decades, associated with affluent classes (Nandy 2002: 61-88), and may lead to stronger boundaries between religious groups because conservatives may reserve socializing for co-religionists (Nimbark 2004). To account for this possible effect on collective religiosity I include a measure of conservative political orientation: "In political matters, people talk of 'the left' and 'the right.' How would you place your views on this scale, generally speaking?" Higher scores indicate conservative political orientation. Responses are coded with a range of 0-6. Respondents who answered "don't know" are coded as 3.

To ensure that the key predictors of interest are not simple proxy measures for religiosity, I control for deity salience, prayer frequency, and religious attendance in analyses. Prayer frequency is reversed and ranges from 0 (never) to 6 (every day). As a measure of deity salience, I use an item that asks respondents how important God is in their life. The WVS codes this variable from 1 ("not at all important") to 3 ("very important"). Religious attendance is a question that asks respondents how often they attend religious services outside of weddings and funerals. This is an eight point variable ranging from "practically never" to "more than once a week." To confirm that religious attendance and religious social capital are not too highly correlated, I inspected their bivariate correlation $(0.241$, $p<0.0001)$.

Finally, because Indian temple traditions in North and South India have basic differences in worship patterns, rituals, and group oriented religious practice (Babb 1975; Kurien 2007: 9, 100), this study includes a dichotomous region variable for Northern region $(0,1)$. North includes: Assam, Bihar, Chhatisgarh, Delhi, Gujarat, Haryana, Jharkhand, Madhya Pradesh, Maharashtra, Orissa, Punjab, Rajasthan, Uttar Pradesh, and West Bengal. South is: Andhra Pradesh, Karnataka, Kerala, and Tamil Nadu. Descriptive statistics are presented in Table 1. 
Table 1 Descriptive statistics for all variables

\footnotetext{
a "I'm going to ask how often you do various things. For each activity, would you say you do them every week; once or twice a month; only a few times a year; or not at all? Spend time with: ...people at your temple, mosque or gurudwara"
}

\begin{tabular}{|c|c|c|c|c|}
\hline Variable & Mean & SD & Min. & Max. \\
\hline Female & 0.415 & 0.493 & 0 & 1 \\
\hline Age & 3.125 & 1.368 & 1 & 6 \\
\hline Education & 2.583 & 2.252 & 0 & 8 \\
\hline Married & 0.907 & 0.291 & 0 & 1 \\
\hline Children & 2.707 & 1.577 & 0 & 8 \\
\hline North & 0.794 & 0.405 & 0 & 1 \\
\hline Political conservatism & 3.165 & 1.241 & 0 & 6 \\
\hline Deity salience & 2.892 & 0.450 & 1 & 3 \\
\hline Prayer & 4.368 & 1.915 & 0 & 6 \\
\hline Religious attendance & 3.601 & 1.660 & 0 & 6 \\
\hline Urbanism & 3.064 & 2.058 & 1 & 8 \\
\hline Social class & 3.643 & 1.445 & 1 & 9 \\
\hline \multicolumn{5}{|l|}{ Caste } \\
\hline Dalit castes & 0.188 & 0.391 & 0 & 1 \\
\hline $\mathrm{OBC}$ castes & 0.566 & 0.496 & 0 & 1 \\
\hline Upper castes & 0.244 & 0.430 & 0 & 1 \\
\hline \multicolumn{5}{|l|}{ Religious social capital ${ }^{\mathrm{a}}$} \\
\hline Not at all & 0.185 & 0.388 & 0 & 1 \\
\hline Few times a year & 0.237 & 0.425 & 0 & 1 \\
\hline Once a month & 0.285 & 0.452 & 0 & 1 \\
\hline Weekly & 0.293 & 0.455 & 0 & 1 \\
\hline
\end{tabular}

\section{Results}

The outcome under consideration is religious bonding capital. Since the primary objective of this study is to test for the effects of urban residence and social positions on religious bonding, I limit discussion of control variables to their relevance for the hypotheses at hand.

Table 2 presents the results of a multinomial logistic regression on Hindus in the sample. The model indicates the increasing or decreasing odds of reporting a particular level of religious bonding in comparison with spending no time with people at one's place of worship (e.g., the odds of spending weekly time over spending no time at all). Table 2 is shown as a backdrop to the interaction effect model that follows, but it is also used as a direct test of Hypothesis 1 . Results indicate that, net of other factors including social class and caste, there is a significant and positive association between urbanism and the odds of reporting religious bonding at all levels as compared with reporting no bonding capital. This relationship between urbanism and bonding is the strongest for reporting weekly time spent as compared with the contrast category, spending no time at all with people at one's place of worship. The results here strongly support Hypothesis 1 .

Among the other variables of interest in the model, it is worth noting that social class shows no statistically significant association with the odds of religious bonding at any level. In this main effects model, upper castes are the only caste group associated with bonding. But interestingly, upper castes have significantly decreasing odds of being associated with all three levels of religious bonding, as compared with spending no time 
Table 2 Multinomial logistic regression of religious social capital

\begin{tabular}{llll}
\hline & \multicolumn{2}{l}{ Time spent with people at place of worship ${ }^{\mathrm{a}}$} & \\
\cline { 2 - 4 } & Weekly & Once or twice a month & A few times a year \\
\hline Female & $0.511(0.206)^{* * *}$ & $0.684(0.200)$ & $0.500(0.208)^{* * *}$ \\
Age & $1.092(0.079)$ & $0.898(0.079)$ & $1.011(0.080)$ \\
Education & $0.934(0.060)$ & $1.015(0.059)$ & $0.986(0.061)$ \\
Married & $0.620(0.367)$ & $0.491(0.352)^{*}$ & $0.631(0.365)$ \\
Children & $0.904(0.072)$ & $1.062(0.070)$ & $0.944(0.072)$ \\
North & $2.612(0.306)^{* *}$ & $0.771(0.272)$ & $0.714(0.277)$ \\
Political conservatism & $1.228(0.079)^{* *}$ & $0.975(0.076)$ & $1.069(0.079)$ \\
Deity salience & $1.589(0.240)$ & $1.454(0.192)$ & $1.914(0.218)^{* *}$ \\
Prayer & $1.495(0.060)^{* * *}$ & $1.149(0.054)^{*}$ & $1.078(0.054)$ \\
Religious attendance & $1.264(0.065)^{* * *}$ & $1.257(0.063)^{* * *}$ & $1.087(0.065)$ \\
Urbanism & $1.207(0.059)^{* *}$ & $1.175(0.059)^{* *}$ & $1.158(0.061)^{*}$ \\
Social class & $1.133(0.079)$ & $1.003(0.080)$ & $0.961(0.085)$ \\
Dalit castes & $0.834(0.264)$ & $0.849(0.252)$ & $0.860(0.260)$ \\
Upper castes & $0.471(0.243)^{* *}$ & $0.470(0.240)^{* *}$ & $0.583(0.249)^{*}$ \\
$N$ & 1,136 & & \\
\hline Ores & & &
\end{tabular}

Odds ratios and standard errors are presented

a The reference category is "not at all"

b The contrast category is OBC castes

$* p<0.05$; ** $p<0.01$; *** $p<0.001$ (two-tailed tests)

with people at their temple. This is important because it means that the positive association between upper castes and bonding as shown in the next model (Table 3) is not simply because upper castes are in greater number in more urban locations or that upper castes are generally more likely to be associated with religious bonding because of expectations that high caste be more religious. The results in Table 2 show just the opposite, net of sociodemographics and religion controls, upper castes are significantly less likely to engage in every level of religious bonding. ${ }^{7}$ Sign switching is sometimes an indication of multicollinearity. In order to assess this possibility, I inspected a correlation matrix and estimated a separate OLS regression model. There is no indication that multicollinearity is a problem (all VIF scores were less than 2).

The model in Table 3 tests Hypotheses 2 and 3. In order to assess whether the interaction between caste and urbanism affects the odds of reporting greater religious bonding, the three outcome points are compared with reporting no time spent with people at one's place of worship. Net of demographic, religion, and social class predictors in the model, the odds ratio for "weekly" religious bonding is significant for urban upper castes. Specifically, the odds of spending weekly time with people at one's temple go up by $32 \%$ for upper castes with each unit increase in urbanism. It is also revealing that in comparison, greater urbanism is not associated with increasing odds of reporting higher religious bonding for Dalit castes as compared with $\mathrm{OBC}$ castes or for $\mathrm{OBC}$ castes as compared with

${ }_{7}$ I also conducted a $t$-test to see if upper castes have in general a higher mean level of religious bonding than all other casts. They do not $(p=0.207)$. 
Table 3 Multinomial logistic regression of the interaction between class or caste and urbanism on religious social capital

\begin{tabular}{llll}
\hline & \multicolumn{2}{l}{ Time spent with people at place of worship ${ }^{\mathrm{a}}$} & \\
\cline { 2 - 4 } & Weekly & Once or twice a month & A few times a year \\
\hline Female & $0.520(0.208)^{* * *}$ & $0.696(0.201)$ & $0.520(0.209)^{* *}$ \\
Age & $1.098(0.080)$ & $0.898(0.080)$ & $1.005(0.081)$ \\
Education & $0.932(0.060)$ & $1.012(0.059)$ & $0.983(0.062)$ \\
Married & $0.668(0.370)$ & $0.515(0.355)$ & $0.650(0.368)$ \\
Children & $0.912(0.073)$ & $1.068(0.070)$ & $0.944(0.072)$ \\
North & $2.304(0.312)^{* *}$ & $0.696(0.279)$ & $0.619(0.285)$ \\
Political conservatism & $1.231(0.079)^{* *}$ & $0.974(0.075)$ & $1.067(0.079)$ \\
Deity salience & $1.539(0.244)$ & $1.399(0.195)$ & $1.838(0.220)^{* *}$ \\
Prayer & $1.523(0.062)^{* * *}$ & $1.165(0.055)^{* *}$ & $1.096(0.055)$ \\
Religious attendance & $1.261(0.065)^{* * *}$ & $1.256(0.063) * * *$ & $1.086(0.065)$ \\
Urbanism & $1.070(0.079)$ & $1.076(0.076)$ & $1.070(0.079)$ \\
Social class & $1.255(0.118)$ & $1.131(0.114)$ & $1.176(0.120)$ \\
Dalit castes ${ }^{\mathrm{b}}$ & $1.024(0.551)$ & $1.049(0.505)$ & $1.376(0.505)$ \\
Upper castes & $0.766(0.332)$ & $0.663(0.323)$ & $0.708(0.336)$ \\
Social class * urbanism & $1.043(0.036)$ & $1.051(0.036)$ & $1.109(0.038)^{* *}$ \\
Dalit castes $*$ urbanism & $1.105(0.182)$ & $1.097(0.169)$ & $1.219(0.170)$ \\
Upper castes $*$ urbanism & $1.316(0.119)^{*}$ & $1.198(0.118)$ & $1.080(0.121)$ \\
$N$ & 1,136 & & \\
\hline Odds & & &
\end{tabular}

Odds ratios and standard errors are presented

a The reference category is "not at all"

b The contrast category is OBC castes

$* p<0.05$; ** $p<0.01$; *** $p<0.001$ (two-tailed tests)

upper castes. This pattern signals that a unique process seems to be at work for upper castes in cities because urbanism does not have the same effects for the other major caste groups. These results provide evidence for Hypothesis 2 and also suggest support for the theorized mechanisms - not only a critical mass, but also a sense of threat to traditional authority experienced by upper castes living in larger cities could also be drawing them toward greater religious bonding out of a longing for moral order.

The interaction between upper castes and urbanism yields different results than the social class interaction effect. Rather than a significant association with the greatest level of religious social capital, the interaction effect is only significant for spending time with fellow temple-goers a few times a year. For each unit increase in social class and each unit increase in urbanism, the odds of reporting seeing people at one's temple "a few times a year" go up by $11 \%$. This finding provides some weak support for Hypothesis 3 , but the lack of significant urban social class effects on "weekly" or "monthly" social capital gives caution to connecting this finding with a subcultural theory of urbanism, which envisions more recurrent social interaction than "a few times a year." There is no evidence that a strong source of Hindu religious bonding in cities can be found in higher social class position. 


\section{Discussion and Conclusions}

This paper has sought to contribute to discussions in the literature on community studies, social capital, and the sociology of religion in India by linking ethnographic insights from India with social theories of group behavior and attempting to unravel factors shaping Hindu religious social capital. The study has been prompted both by Fischer's (1995) proposal that the subcultural theory of urbanism should be explored in non-Western contexts, and the theory's applicability to substantive theoretical debates between secularization theorists (Norris and Inglehart 2004) and multiple modernities scholars (see Smith 2008: 1569-1581). Contemporary India provides an important case with which to examine urban religious social capital, not only because of its size, religious significance, and recent urbanization, but because qualitative research from India documents increases in religious bonding in Indian cities and points to two distinct social factors associated with this bonding - social class and caste. Deriving hypotheses from these theoretical links, I tested whether heightened urban religious bonding is better explained by one or other of these two social factors. Recent scholarship asserts that though these two characteristics are historically related to one another, there is evidence that they are becoming increasingly loosely coupled in modern India (Mayer 1997; Krishna 2002: 38; Sheth 1999), and the present paper's findings confirm the value of analyzing the independent effects of caste and class. Specifically, in support of previous literature emphasizing the importance of caste (Swallow 1982) and contrary to social class oriented explanations (Kakar 1991; Singer 1972), I found that upper caste status is associated with the highest level of religious bonding in urban India and class is not. This is not to say that social class explanations of bonding might not hold with other conceptions of social class (e.g., certain occupational groups such as information technology workers, or a particularly defined income bracket). But the present study finds no confirmation that more affluent classes are associated with greater religious bonding in urban India. Researchers should continue to examine how social class-bonding hypotheses might be better measured and modeled. For the present, I provide evidence that religious bonding is tied specifically to upper caste status in the Indian city, and this finding warrants more explanation.

What could be drawing the urban upper castes to greater collective religious interaction? A plausible interpretation of these results is found in uniting complementary lines of previous theorizing and research. Giddens (1991: 185) argues that modernity fosters a sense of crisis that people assuage through relationships, and accounts of urban "devotional community" involvement in India resonate with this argument (Babb 1987: 222). Additionally, Fischer (1995) maintains that intense social bonding in cities is a process of subcultural urbanism facilitated by critical mass and accessibility of culturally similar people in cities, and simultaneous experiences of threat: increased contact with diverse outgroups and changing norms in cities. These processes draw the group together while at the same time promote a sense of menace, thus reinforcing boundaries and further bolstering solidarity within the subculture. Subcultural urbanism may particularly relate to bonding along religious lines because of the "moral underpinnings of trust and social capital," and the meaning-giving role of religious institutions (Vaisey 2007: 865; see also Etzioni 2001; Smith 2003; Smith et al. 1998: 91). Groups organized around religious culture are also very effective at adjusting action (in this case increasing bonding activity) in unsettled circumstances (Swidler 1986), not least because of the culturally rooted array of polysemous resources that religious groups often have at their disposal, such as "symbols, language, or texts" (Sewell 2005: 142). With this background in mind, it is unsurprising that urbanism should foster bonding capital along religious lines. But the analyses presented here show 
that upper castes experience religious bonding, more than other castes. As outlined above, upper caste urbanites may be increasingly drawn to religious bonding because of their size, density, and out-group friction in cities, yet this alone does not adequately explain why upper castes are more likely to engage in religious bonding than other castes in the urban environment.

One plausible mechanism for this unique upper caste pattern may be that upper caste Hindus use bonding with fellow devotees to renew a sense of moral order amid feelings of disorientation and diminishing traditional caste authority in cities-a traditional authority that does not similarly benefit other caste groupings. For upper caste Hindus, the experience of urbanization as "unsettling" times and as morally disordering environment is marked by challenges to traditional patterns of caste life, ascendancy, and deeply held views of human hierarchy. ${ }^{8}$ Through bonding with other devotees, upper caste individuals seek to re-engage Hinduism with their modern situation and renew a sense of moral order (Swallow 1982). This response comes from feelings of out-group threat that are not experienced by other castes in the same way, to the same degree, and likely does not produce the same need for strengthening "morally orienting collective identity" (Smith et al. 1998: 90). Going forward, it would take more work to confirm whether the specificity of this mechanism matches the findings presented in this study, but the data are at least consistent with such explanations.

Since the findings of this study are based on a survey of India, the results are not necessarily generalizable to other cultures or locations. Involvement in religious community may not be the pattern that emerges in all societies undergoing urbanization and shifts in social norms, though Yang (2005) has observed comparable patterns of religious involvement among urban sophisticates in another developing Asian nation. But other cases may be considerably different. Due to unique historical paths, other cultures or societies may have a disposition to seek belonging and meaning in political or social movements sans religion (Giddens 1991). In this way, modernity's juggernaut may veer unexpectedly (Giddens 1990), and proceed along multiple trajectories (Eisenstadt 2000; Martin 2005).

In the end, this paper is limited in several ways. The most proximate mechanisms linking urbanism and caste to religious bonding - density, threat, and moral order-must be left theorized and approximated, but not specifically tested. This paper's analyses only contribute to groundwork for understanding upper caste urbanites' greater religious bonding, but they do not reveal the particular reasons for these patterns of bonding activity. Additionally, the uniqueness of the measure of religious bonding in this study presents limitations. The regularity of time spent in the company of fellow temple worshippers is only a proxy for social capital and not a direct measure of the quality and quantity of relationships. ${ }^{9}$ Future researchers should refine these measures and further test theories of religious bonding in India.

Though other limitations of this paper could be discussed, one weakness readily apparent to readers is the cross-sectional nature of the data. The constraints imposed by the nature of available data necessarily restrict the precision of this paper's findings. Crosssectional data do not allow variables to be ordered in time and so it is conceivable that

\footnotetext{
${ }^{8}$ Fuller (2004: 256) contends that "inequality is deeply entrenched in Hinduism and Indian society, at both ideological and institutional levels, despite the fact that the principle and practice of equality clearly have gained ground in contemporary India, particularly in the political, economic, and legal fields. In the face of this development, however, Hinduism itself tends to represent a predominantly conservative force ...".

${ }^{9}$ I thank an anonymous reviewer for this pointing out this limitation.
} 
some of the effects discussed here might run in the opposite direction. For example, rather than seeing social class as a source of religious bonding, salutary relations with co-religionists at the temple could spill over into connections for finding a job or advancing career interests (Granovetter 1973; Wuthnow 2002), leading to upward economic mobility. While such alternate directions cannot be ruled out, the present study has tried to base hypotheses on sociological theories that best correspond to qualitative literature from India. This literature sees class and caste as shaping urban religious bonding.

It is also worth noting that though the World Values Survey provides one of the few windows into national religious life in India, future research could be advanced with survey questions more specifically attuned to the varying particularities of Indian religious participation. The design of such all-India survey questions would prove a daunting task considering the diversity of religious life simply within Hindu religious traditions, let alone its cognate faiths and varied accretions in Indian Islam and Christianity. Though more research is clearly needed, the present paper opens a path in the study of a neglected social sphere in an under-examined but important nation. The author is aware of no other recent national survey research on contemporary religious life in urban India. Future work should not only fill out the story of the impact of urbanization on religious traditions in India, but also explore the differing social consequences of life within India's varied religious traditions. In India, the complexity and scale of social and religious life looms large for sociological inquiry.

Acknowledgments The author is grateful to Paul Castronova, Phillip Connor, Paul Froese, Carson Mencken, Charles North, Rodney Stark, Brandon Vaidyanathan, the editor, and anonymous referees for comments on an earlier draft of this article.

\section{References}

Appadurai, A., \& Breckenridge, C. A. (1976). The South Indian temple: Authority, honor, and redistribution. Contributions to Indian Sociology, 10, 187-209.

Appadurai, A., \& Breckenridge, C. A. (1995). Public modernity in India. In C. A. Breckenridge (Ed.), Consuming modernity: Public culture in a South Asian world (pp. 1-22). Minneapolis: University of Minnesota Press.

Babb, L. (1975). The divine hierarchy: Popular Hinduism in central India. New York: Columbia University Press.

Babb, L. (1987). Redemptive encounters: Three modern styles in the Hindu tradition. Delhi: Oxford University Press.

Bayly, S. (1999). The new Cambridge history of India. Vol. IV.3: Caste, society and politics in India from the eighteenth century to the modern age. Cambridge: Cambridge University Press.

Béteille, A. (1991). The reproduction of inequality: Occupation, caste and family. Contributions to Indian Sociology, 25(1), 3-28.

Béteille, A. (1992). The backward classes in contemporary India. Delhi: Oxford University Press.

Béteille, A. (1997). Hierarchy and its discontents: Culture and the politics of consciousness in caste society. Journal of the Royal Anthropological Institute, 3(4).

Beyerlein, K., \& Hipp, J. R. (2005). Social capital, too much of a good thing? American religious traditions and community crime. Social Forces, 84(2), 995-1013.

Bhattcharyya, D. (2004). Interrogating social capital: The Indian experience. New Delhi: Sage.

Borooah, V. K. (2003). Births, infants and children: An econometric portrait of women and children in India. Development and Change, 34(1), 67-103.

Calhoun, C. (1998). Community without propinquity revisited: Communications technology and the transformation of the urban public sphere. Sociological Inquiry, 68(3), 373-397.

Chaudhuri, S. (2009). Sharing cultures: Integration, assimilation and interaction in the Indian urban context. In G. Prato (Ed.), Beyond multiculturalism: Views from anthropology (pp. 189-200). Farnham, England: Ashgate. 
Chibber, P., \& Mishra, S. (1993). Hindus and the Babri Masjid: The sectional basis of communal attitudes. Asian Survey, 33(7), 665-672.

Cohn, B. (1987). An anthropologist among the historians and other essays. Delhi: Oxford University Press.

Commander, S. (1983). The Jajmani system in North India: An examination of its logic and status across two centuries. Modern Asian Studies, 17(2), 283-311.

Das, G. (2002). India unbound: From independence to the global information age (revised ed.). New Delhi: Penguin.

Demerath, N. J. (1965). Social class in American protestantism. Rand McNally sociology series. Chicago: Rand McNally.

Derne, S. (2008). Globalization on the ground: Media and the transformation of culture, class, and gender in India. Los Angeles: Sage.

Desai, S., \& Kulkarni, V. (2008). Changing educational inequalities in India in the context of affirmative action. Demography, 45(2), 245-270.

Deshpande, S. (2003). Contemporary India: A sociological view. New Delhi: Viking Penguin.

Dirks, N. (1987). The hollow crown: Ethnohistory of an Indian kingdom. New York: Cambridge University Press.

Dreze, J., Lanjouw, P., \& Sharma, N. (1999). Economic development in Palanpur, 1957-93. In P. Lanjouw \& N. Stern (Eds.), Economic development in Palanpur over five decades. Oxford: Clarendon Press.

Dumont, L. (1980). Homo hierarchicus: The caste system and its implications (M. Sainsbury, L. Dumont, \& B. Gulati, Trans.). Chicago: University of Chicago Press.

Durkheim, E. (1933). The division of labor in society. New York: Free Press.

Eisenstadt, S. N. (2000). Multiple modernities. Daedalus, 129(1), 1-29.

Etzioni, A. (2001). Is bowling together sociologically lite? Contemporary Sociology, 30(3), 223-224.

Fernandes, L. (2006). India's new middle class: Democratic politics in an era of economic reform. Minneapolis: University of Minnesota Press.

Field, J. (2008). Social capital (2nd ed.). New York: Routledge.

Finke, R., \& Stark, R. (2005). The churching of America, 1776-2005: Winners and losers in our religious economy (2nd ed.). New Brunswick, NJ: Rutgers University Press.

Fischer, C. S. (1975). Toward a subcultural theory of urbanism. American Journal of Sociology, 80(6), 1319-1341.

Fischer, C. S. (1995). The subcultural theory of urbanism: A twentieth-year assessment. American Journal of Sociology, 101(3), 543-577.

Fukuyama, F. (2001). Social capital, civil society and development. Third World Quarterly, 22(1), 7-20.

Fuller, C. J. (Ed.). (1997). Caste today. Delhi: Oxford University Press.

Fuller, C. J. (2004). The camphor flame: Popular Hinduism and society in India (2nd ed.). Princeton: Princeton University Press.

George, S. (2005). When women come first: Gender and class in transnational migration. Berkeley: University of California Press.

Giddens, A. (1990). The consequences of modernity. Stanford, CA: Stanford University Press.

Giddens, A. (1991). Modernity and self-identity: Self and society in the late modern age. Stanford, CA: Stanford University Press.

Granovetter, M. S. (1973). The strength of weak ties. American Journal of Sociology, 78(6), 1360-1380.

Handy, R. T. (1960). The American religious depression, 1925-1935. Church History, 29(1), 3-16.

Harriss, J. (2003). The great tradition globalizes: Reflections on two studies of 'the industrial leaders' of Madras. Modern Asian Studies, 37(2), 327-362.

Hertel, B. R. (1977). Church, sect, and congregation in Hinduism: An examination of social structure and religious authority. Journal for the Scientific Study of Religion, 16(1), 15-26.

Hurlbert, J. S., Haines, V. A., \& Beggs, J. J. (2000). Core networks and tie activation: What kinds of routine networks allocate resources in nonroutine situations? American Sociological Review, 65(4), 598-618.

Jaffrelot, C., \& van der Veer, P. (2008). Patterns of middle class consumption in India and China. Thousand Oaks, CA: Sage.

Kakar, S. (1991). Shamans, mystics and doctors: A psychological inquiry into India and its healing traditions. Chicago: The University of Chicago Press.

Krishna, A. (2002). Active social capital: Tracing the roots of development and democracy. New York: Columbia University Press.

Krishna, A. (2007). How does social capital grow? A seven-year study of villages in India. Journal of Politics, 69(4), 941-956.

Kurien, P. A. (2007). A place at the multicultural table: The development of an American Hinduism. New Brunswick, NJ: Rutgers University Press. 
Levitt, P. (2004). Redefining the boundaries of belonging: The institutional character of transnational religious life. Sociology of Religion, 65(1), 1-18.

Li, Y., Savage, M., \& Warde, A. (2008). Social mobility and social capital in contemporary Britain. British Journal of Sociology, 59(3), 391-411.

Martin, D. (2005). On secularization: Toward a revised general theory. Burlington, VT: Ashgate.

Mayer, A. (1997). Caste in an Indian village: Change and continuity 1954-1992. In C. J. Fuller (Ed.), Caste today (pp. 32-64). Delhi: Oxford University Press.

Menard, S. (2001). Applied logistic regression analysis. Thousand Oaks, CA: Sage.

Mendelsohn, O., \& Vicziany, M. (1998). The untouchables: Subordination, poverty and the state in modern India. New York: Oxford University Press.

Michaels, A. (2004). Hinduism: Past and present (B. Harshav, Trans.). Princeton: Princeton University Press.

Milner, M., Jr. (1994). Status and sacredness: A general theory of status relations and an analysis of Indian culture. Oxford: Oxford University Press.

Moody, J., \& Paxton, P. (2009). Building bridges. American Behavioral Scientist, 52, 1491-1506.

Nandy, A. (2002). Time warps: Silent and evasive pasts in Indian politics and religion. New Brunswick, NJ: Rutgers University Press.

Narayanan, V. (1999). Brimming with bhakti, embodiments of Shakti: Devotees, deities, performers, reformers, and other women of power in the Hindu tradition. In A. Sharma \& K. K. Young (Eds.), Feminism and world religions (pp. 25-77). Albany: State University of New York Press.

Nimbark, A. (2004). Paradoxes of media-reflected religiosity among Hindu Indians. In T. Carnes \& F. Yang (Eds.), Asian American religions: The making and remaking of borders and boundaries (pp. 98-111). New York: New York University Press.

Nooney, J., \& Woodrum, E. (2002). Religious coping and church-based social support as predictors of mental health outcomes: Testing a conceptual model. Journal for the Scientific Study of Religion, 41(2), 359-368.

Norris, P., \& Inglehart, R. (2004). Sacred and secular: Religion and politics worldwide. New York: Cambridge University Press.

Paxton, P. (2002). Social capital and democracy: An interdependent relationship. American Sociological Review, 67(2), 254-277.

Portes, A. (1998). Social capital: Its origins and applications in modern sociology. Annual Review of Sociology, 24, 1-24.

Portes, A., \& Sensenbrenner, J. (1993). Embeddedness and immigration: Notes on the social determinants of economic action. American Journal of Sociology, 98(6), 1320-1350.

Putnam, R. D. (2000). Bowling alone: The collapse and revival of American community. New York: Simon \& Schuster.

Putnam, R. (2002). Bowling together: The United States of America. The American Prospect. February 11.

Ray, I. D., \& Das, T. K. (2004). Exploring the market of Hindu religion. Paper presented at the third annual conference on religion, economics and culture Kansas City, October 22-24, 2004.

Rudolph, L., \& Rudolph, S. (1967). The modernity of tradition: Political development in India. Chicago: University of Chicago Press.

Sewell, W. H. (2005). Logics of history: Social theory and social transformation. Chicago: University of Chicago Press.

Shah, A. M. (2006). Sects and Hindu social structure. Contributions to Indian Sociology, 40(2), 209-248.

Sheth, D. L. (1999). Secularisation of caste and making of new middle class. Economic and Political Weekly, 34(34/35), 2502-2510.

Singer, M. B. (1972). When a great tradition modernizes: An anthropological approach to Indian civilization. New York: Praeger Publishers.

Singh, K. S. (2002). People of India: An introduction. New York: Oxford University Press.

Smith, C. (2003). Moral, believing animals: Human personhood and culture. New York: Oxford University Press.

Smith, C. (2008). Future directions in the sociology of religion. Social Forces, 86, 1561-1589.

Smith, C., Emerson, M., Gallagher, S., Kennedy, P., \& Sikkink, D. (1998). American Evangelicalism: Embattled and thriving. Chicago, Il: University of Chicago Press.

Sridharan, E. (2004). The growth and sectoral composition of India's middle class: Its impact on the politics of economic liberalization. India Review, 3(4), 405-428.

Srinivas, M. N. (1965). Religion and society among the Coorgs of South India. New York: Asia Publication House.

Srinivas, M. N. (1966). Social change in modern India. Berkeley: University of California Press. 
Stark, R. (1996). The rise of Christianity: A sociologist reconsiders history. Princeton, NJ: Princeton University Press.

Swallow, D. A. (1982). Ashes and powers: Myth, rite and miracle in an Indian God-Man's Cult. Modern Asian Studies, 16(1), 123-158.

Swidler, A. (1986). Culture in action: Symbols and strategies. American Sociological Review, 51(2), $273-286$.

Vaisey, S. (2007). Structure, culture, and community: The search for belonging in 50 urban communes. American Sociological Review, 72(6), 851-873.

Van der Veer, P. (1994). Religious nationalism: Hindus and Muslims in India. Berkeley: University of California Press.

Vanneman, R., Noon, J., Sen, M., Desai, S., \& Shariff, A. (2006). Social networks in India: Caste, tribe, and religious variations. Paper presented at annual meetings of the Population Association of America, Los Angeles, CA.

Varma, P. K. (1998). The Great Indian middle class. New Delhi, India: Penguin.

Vertovec, S. (2000). The Hindu diaspora: Comparative patterns. London: Routledge.

Waghorne, J. P. (2004). Diaspora of the gods: Modern Hindu temples in an urban middle-class world. New York: Oxford University Press.

Warrier, M. (2003). Process of secularization in contemporary India: Guru faith in the Mata Amritanandamayi Mission. Modern Asian Studies, 37(1), 213.

Warrier, M. (2005). Hindu selves in a modern world: Guru faith in the Mata Amritanandamayi mission. New York: Routledge.

Weber, M. (1968). Economy and society: An outline of interpretive sociology. Berkeley: University of California Press.

Williams, R. B. (1992). Sacred threads of several textures. In A. Sacred \& R. B. Williams (Eds.), Thread: Modern transmission of Hindu traditions in india, abroad (pp. 228-257). Chambersburg, PA: Anima Press.

Wirth, L. (1938). Urbanism as a way of life. The American Journal of Sociology, 44(1), 1-24.

Wuthnow, R. (1987). Meaning and moral order: Explorations in cultural analysis. Berkeley: University of California Press.

Wuthnow, R. (2002). Religious involvement and status-bridging social capital. Journal for the Scientific Study of Religion, 41(4), 669-684.

Yang, F. (2005). Lost in the market, saved at McDonald's: Conversion to Christianity in urban China. Journal for the Scientific Study of Religion, 44(4), 423-441. 
Copyright of Social Indicators Research is the property of Springer Science \& Business Media B.V. and its content may not be copied or emailed to multiple sites or posted to a listserv without the copyright holder's express written permission. However, users may print, download, or email articles for individual use. 